\title{
A novel approach with holmium laser ablation for endoscopic management of intrahepatic biliary stricture
}

\author{
Jianying Lou*, Qida Hu², Tao Ma², Wei Chen², Ji Wang ${ }^{2}$ and Prasoon Pankaj ${ }^{1}$
}

\begin{abstract}
Background: Hepatolithiasis, featuring high incidence, severe symptoms, and common recurrence, poses a heavy disease burden. Endoscopic management provides an opportunity to cure hepatolithiasis, but fails to properly resolve biliary stricture without additional interventional techniques. An innovative approach towards endoscopic management of biliary stricture is required.

Methods: Holmium laser ablation was applied to biliary strictures via endoscopic access. Patients' demographic, operative, and follow-up data after receiving holmium laser ablation were retrospectively collected for analysis.

Results: A total of 15 patients (4 males and 11 females) underwent stricture ablation by holmium laser via cholangioscopy. All the patients successfully received holmium laser ablation, indicating a technical success rate of $100 \%$. No postoperative mortality or no major perioperative complication was observed. During the follow-up period, the recurrence-free rate was $73 \%$ at 2 years and $67 \%$ at 5 years.

Conclusions: We successfully developed a novel technique of biliary stricture removal by cholangioscopic holmium laser ablation with satisfying clinical outcomes.
\end{abstract}

Keywords: Holmium laser ablation, Cholangioscopy, Hepatolithiasis, Biliary stricture

\section{Background}

Hepatolithiasis is a common biliary disorder found in Asian population, with an incidence rate ranging from 2 to $25 \%$ in Southeastern Asia [1-4]. Hepatolithiasis, characterized by intrabiliary stone formation, results in bile stasis, and sometimes recurrent cholangitis. Patients suffering from the disease also bear high risk of stone recurrence even after surgical treatment, mainly due to unsolved etiological problems such as anatomical biliary stricture or transient portal bacteremia [5, 6]. Additionally, hepatolithiasis is also an established risk factor for cholangiocarcinoma with very poor prognosis [4]. Therefore, the high incidence, the severe symptoms, and the common recurrence altogether contribute to a heavy disease burden on the society and a low quality of life for the patients.

\footnotetext{
* Correspondence: loujianying@zju.edu.cn

${ }^{1}$ Department of Hepatobiliary and Pancreatic Surgery, Second Affiliated Hospital, Zhejiang University School of Medicine, 88 Jiefang Rd, Hangzhou 310009, Zhejiang, China

Full list of author information is available at the end of the article
}

Current principles for hepatolithiasis management include stone clearance, biliary stricture removal, proper bile drainage, and resection of severely involved liver, aiming to reduce the postoperative recurrence rate [7]. A variety of methods have been practiced for clinical hepatolithiasis management. One major approach is hepatic resection, which simultaneously resolves the problems of intrahepatic stones and biliary stricture by en-bloc surgical removal $[8,9]$. Hepatic resection could also benefit the patients with reduced risks of cholangiocarcinoma [10], because the technique allows for complete removal of the liver parenchyma with the potential of carcinogenesis. Another approach is endoscopic removal of intrahepatic stone, featured by minimally invasive lithotomy that significantly enhances postoperative recovery and reduces hospital stay $[11,12]$. The endoscopic lithotomy procedure could be achieved by either choledochoscopy via an exploratory incision into the common bile duct or cholangioscopy via percutaneous transhepatic approach $[6,11-14]$. In particular, the patients with recurrent

(c) The Author(s). 2019 Open Access This article is distributed under the terms of the Creative Commons Attribution 4.0 International License (http://creativecommons.org/licenses/by/4.0/), which permits unrestricted use, distribution, and 
hepatolithiasis, who might have complicated surgical history or insufficient liver remnant, are usually unable to tolerate another major hepatic resection due to severe adhesion or possible postoperative liver function failure. Endoscopic approach proposes an opportunity to cure hepatolithiasis for those "inoperable" patients, but cannot properly resolve biliary stricture without additional interventional techniques.

Currently, only a few methods are available for biliary stricture management, including biliary stent $[15,16]$, balloon dilation [17, 18], radiofrequency ablation [19], and biliary scraper [20]. However, the recurrent rate of hepatolithiasis remains high. Effective management strategy in endoscopic approach for biliary stricture is still required. Here we propose an innovative approach using a holmium:yttrium-aluminum-garnet (Ho:YAG) surgical laser, a widely used technique in lithotripsy, for stricture ablation and complete stone clearance in endoscopic lithotomy.

\section{Methods}

\section{Operative procedures}

An endoscope with a $7.5 \mathrm{~F}$ outer diameter and a $3.6 \mathrm{~F}$ functioning route (Olympus, Japan) was applied for percutaneous cholangioscopy via a T-tube tract or other available access to the biliary tree. Continuous warm $0.9 \%$ saline solution $\left(34-38^{\circ} \mathrm{C}\right)$ was flushed via the functioning route for proper distension of the biliary ducts and clear vision of the surgical field after debris elimination. In situation of an encountered biliary stricture, a $200 \mathrm{~mm}$ optical fiber was inserted into the functioning route to access the stricture site, with the other end connected to a $60 \mathrm{~W}$ solid-state holmium unit consisted of a VersaPulse PowerSuite holmium laser (Lumenis, Yokneam, Isreal) and a control module (ZTC, Xiamen, China). The laser beam frequency was set to $6-10 \mathrm{~Hz}$, and the energy was set to $0.5-1.0 \mathrm{~J}$.

We initiated stricture ablation using the Ho:YAG laser at the superficial inner surface of the biliary stricture, and carefully cut the stricture in a spiral manner within the depth of $1 \mathrm{~mm}$ (Fig. 1). The horizontal or transverse cutting, other than the spiral cutting, could eventually damage the adjacent vascular structure, which could lead to catastrophic consequences such as massive bleeding and should therefore be avoided. Mild biliary bleeding could be well controlled by holmium laser cautery using same beam energy and frequency as laser cutting. Active biliary bleeding should be managed with laser cautery at first, or be managed with prepared open hepatectomy to remove the bleeding lesions if unsuccessful with laser cautery. In most circumstances of stricture removal, the biliary stricture would loosen to let through cholangioscopy, after cutting the biliary stricture on less than $1 / 4$ spiral of the inner surface. The reason might be that lysis of the fibrosis adhesion in part of the stricture tissue subsequently resulted in spontaneous lysis of the whole stricture. The cholangioscopy was then able to access the obstructed segment of the liver to continue the lithotripsy. The holmium laser ablation could be repeatedly applied to further biliary stricture until the biliary tree was free of stricture.

\section{Study design}

We retrospectively reviewed the patients who underwent Ho:YAG laser stricture ablation from May 2012 to June 2015 at the Department of Hepatobiliary and Pancreatic

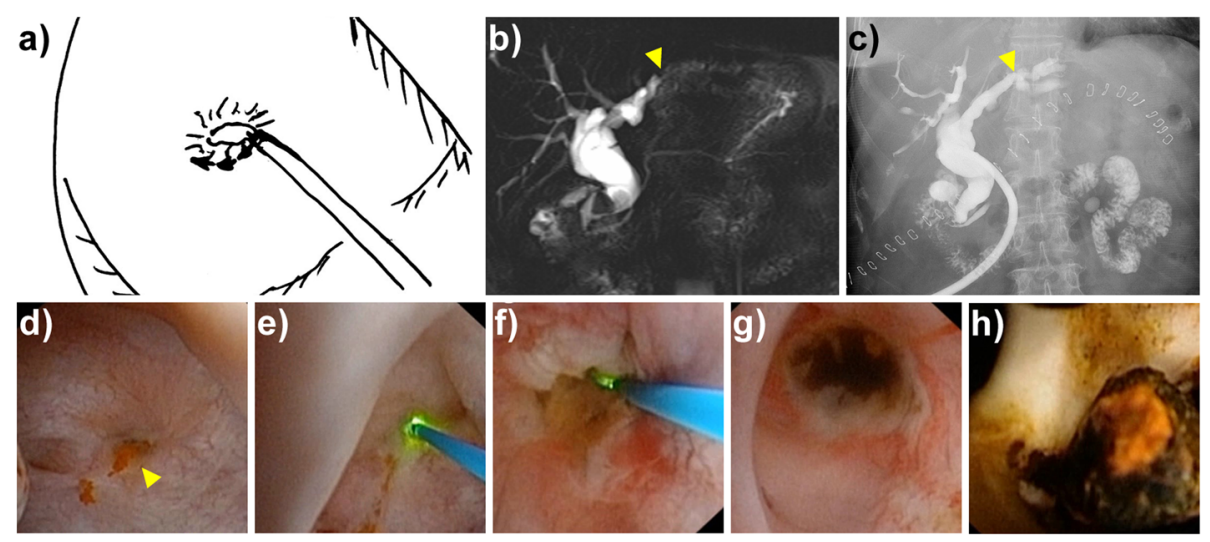

Fig. 1 Holmium laser ablation for biliary stricture in a representative case, who had biliary stricture at the left hepatic duct. a A cartoon demonstration of biliary stricture ablation by laser ablation via T tube access. The arrows indicate the spiral cutting route in laser ablation. $\mathbf{b}$ Preoperative magnetic resonance cholangiopancreatography (MRCP) did not show the visualization of the distal biliary duct in the left lobe. $\mathbf{c}$ Postoperative T-tube cholangiography study showed visualization of the distal biliary duct. $\mathbf{d}$ The biliary stricture visualized during cholangioscopy. The yellow triangle indicates the stricture. e Initiation of holmium laser ablation at the stricture. $\mathbf{f}$ Holmium laser ablation in a spiral cutting manner. $\mathbf{g}$ Laser ablation accomplished, with relieved stricture allowing for cholangioscopy to pass through. $\mathbf{h}$ Multiple pigment stones observed in the distal biliary duct beyond the stricture location 
Surgery, Second Affiliated Hospital, Zhejiang University School of Medicine. All the medical records from the electronic medical record system and the archived documents were used to collect demographic, operative, and follow-up data. Patients' age, gender, stricture condition, procedure duration, and status of biliary stones were collected as variables of interests. Subsequent medical records after stricture ablation were analyzed to determine clinical success, follow-up duration, occurrence of stricture or stone recurrent. The patients were evaluated with ultrasound sonography after stone clearance. This study was approved by the institutional review board (approval number 2012-355). All the patients signed the informed consent before the procedure.

\section{Statistical analysis}

Data are presented as mean \pm standard deviation (s.d.). Analysis of variance or the nonparametric KruskalWallis test was used to compare continuous factors, and the Pearson $X^{2}$ test was used for categorical variables. Recurrence-free survival analysis was performed to ascertain mean duration from stone clearance to recurrence, with Kaplan-Meier plots constructed. Statistical analyses were performed by Prism 7 (GraphPad, La Jolla, USA).

\section{Results}

A total of 15 patients (4 males and 11 females) underwent stricture ablation by Ho:YAG laser via cholangioscopy (Table 1). Among them, 12 patients were referred from the local medical centers, and the other 3 patients were directly admitted to our center. The average age of the patients was $58 \pm 9$ years old (mean \pm s.d.; median 58 , range 41-70). All patients had biliary stricture with multiple intrahepatic stones. These patients were initially diagnosed as biliary stones at $47 \pm 14$ years old (mean \pm s.d.; median 52, range 23-64), and progressed to biliary stricture requiring operation in $11 \pm 8$ years (mean \pm s.d.; median 10 , range $1-30$ ).

The diagnosis of intrahepatic biliary stricture in all patients was confirmed during the operation. The 15 cases were all presented with multiple pigment stones, among which 5 cases (33\%) had choledocal stones (Table 2). All the cases presented single biliary stricture, with 7 cases in the left lobe, 7 cases in the right lobe mainly in segments VI and VII, and 1 case in the confluent biliary duct. All the patients successfully received Ho:YAG laser ablation of biliary stricture via choledocoscopy or cholangioscopy via routes of previously placed $\mathrm{T}$ tube $(10$ cases), open operation (4 cases), or laparoscopic access (1 case), with a technical success rate of $100 \%$. The total operation time for the initial cholangioscopy with stricture ablation was $47 \pm 12 \mathrm{~min}$ (mean \pm s.d.; range $25-65$ ).
Table 1 Demographic characteristics of included patients

\begin{tabular}{|c|c|c|c|c|}
\hline $\begin{array}{l}\text { Case } \\
\#\end{array}$ & Gender & $\begin{array}{l}\text { Age } \\
\text { (years } \\
\text { old) }\end{array}$ & $\begin{array}{l}\text { Age of initial } \\
\text { hepatolithiasis } \\
\text { diagnosis (years } \\
\text { old) }\end{array}$ & Previous surgical history \\
\hline 1 & Male & 63 & 43 & None \\
\hline 2 & Female & 70 & 60 & $\begin{array}{l}\text { (1) Open cholecystectomy } \\
\text { (2) open common bile } \\
\text { duct exploration (CBDE) }\end{array}$ \\
\hline 3 & Female & 53 & 23 & $\begin{array}{l}\text { (1) Open cholecystectomy } \\
\text { \& CBDE (2) open left lateral } \\
\text { hepatectomy \& CBDE }\end{array}$ \\
\hline 4 & Male & 65 & 60 & $\begin{array}{l}\text { (1) Open cholecystectomy } \\
\& \text { CBDE (2) open left } \\
\text { hemihepatectomy \& CBDE }\end{array}$ \\
\hline 5 & Male & 58 & 52 & $\begin{array}{l}\text { (1) Open cholecystectomy } \\
\text { \& CBDE (2) ERCP with } \\
\text { stone removal }\end{array}$ \\
\hline 6 & Female & 66 & 64 & $\begin{array}{l}\text { Open cholecystectomy \& } \\
\text { CBDE }\end{array}$ \\
\hline 7 & Female & 68 & 58 & $\begin{array}{l}\text { (1) Open cholecystectomy } \\
\text { (2) open CBDE }\end{array}$ \\
\hline 8 & Female & 56 & 41 & $\begin{array}{l}\text { (1) Open cholecystectomy } \\
\text { (2) open CBDE }\end{array}$ \\
\hline 9 & Female & 65 & 52 & $\begin{array}{l}\text { (1) Open cholecystectomy } \\
\text { (2) open CBDE }\end{array}$ \\
\hline 10 & Female & 67 & 61 & Open cholecystectomy \\
\hline 11 & Female & 41 & 31 & $\begin{array}{l}\text { Open cholecystectomy \& } \\
\text { CBDE }\end{array}$ \\
\hline 12 & Female & 58 & 38 & $\begin{array}{l}\text { (1) Open cholecystectomy } \\
\text { (2) open CBDE }\end{array}$ \\
\hline 13 & Male & 48 & 38 & $\begin{array}{l}\text { Open cholecystectomy, } \\
\text { CBDE, left lateral } \\
\text { hepatectomy \& } \\
\text { hepaticojejunostomy }\end{array}$ \\
\hline 14 & Female & 41 & 26 & $\begin{array}{l}\text { (1) Open cholecystectomy } \\
\text { (2) open CBDE }\end{array}$ \\
\hline 15 & Female & 58 & 57 & None \\
\hline
\end{tabular}

$E R C P$ endoscopic retrograde cholangiopancreatography

Specifically, the Ho:YAG ablation procedure took the surgeons only $25 \pm 11 \mathrm{~s}$ (mean \pm s.d.; range $12-44$ ) to open the stricture. The residual stones were then eliminated by subsequent cholangioscopic lithotripsy or stone removal procedures with a median time of 2 sessions (range was no postoperative mortality or major perioperative complication such as biliary hemorrhage or liver failure. Minor discomforts in patients were observed: one patient developed abdominal distension with temporary fever due to incomplete ileus; one patient had fever with the maximum body temperature of $38.3^{\circ} \mathrm{C}$; another patient had diarrhea 3 days post the procedure. These three patients were well managed with conservative treatment and finally discharged.

All patients were then followed up for $48 \pm 12$ months (mean \pm s.d.; median 47 , range $20-68$ ) to obtain the long-term outcome data (Table 3). Four patients had 
Table $\mathbf{2}$ Characteristics of biliary stricture and perioperative parameters

\begin{tabular}{|c|c|c|c|c|c|c|c|}
\hline $\begin{array}{l}\text { Case } \\
\#\end{array}$ & $\begin{array}{l}\text { Location of } \\
\text { the biliary } \\
\text { stricture }\end{array}$ & $\begin{array}{l}\text { Location of } \\
\text { hepatolithiasis }\end{array}$ & $\begin{array}{l}\text { Access route of the } \\
\text { cholangioscopic stricture } \\
\text { ablation }\end{array}$ & $\begin{array}{l}\text { Duration of the initial } \\
\text { cholangioscopy } \\
\text { (mins) }\end{array}$ & $\begin{array}{l}\text { Operative duration of } \\
\text { Ho:YAG laser ablation } \\
\text { (secs) }\end{array}$ & $\begin{array}{l}\text { Subsequent } \\
\text { cholangioscopy } \\
\text { sessions }\end{array}$ & $\begin{array}{l}\text { Major } \\
\text { postoperative } \\
\text { complications }\end{array}$ \\
\hline 1 & Sgts II-III & $\begin{array}{l}\text { Bilateral lobes } \\
\& \text { CBD }\end{array}$ & Laparoscopic & 45 & 12 & 4 & No \\
\hline 2 & Sgts II-III & Bilateral lobes & T tube & 60 & 20 & 4 & No \\
\hline 3 & Sgts VI-VII & $\begin{array}{l}\text { Bilateral lobes } \\
\text { \& CBD }\end{array}$ & T tube & 50 & 32 & 0 & No \\
\hline 4 & $\begin{array}{l}\text { Right hepatic } \\
\text { duct }\end{array}$ & $\begin{array}{l}\text { Right lobe \& } \\
\text { CBD }\end{array}$ & T tube & 55 & 12 & 3 & No \\
\hline 5 & Sgts II-III & Bilateral lobes & T tube & 50 & 12 & 3 & No \\
\hline 6 & $\begin{array}{l}\text { Left hepatic } \\
\text { duct }\end{array}$ & Left lobe & T tube & 50 & 34 & 2 & No \\
\hline 7 & $\begin{array}{l}\text { Left hepatic } \\
\text { duct }\end{array}$ & Left lobe & T tube & 60 & 40 & 2 & No \\
\hline 8 & Sgts VI-VII & $\begin{array}{l}\text { Bilateral lobes } \\
\& \text { CBD }\end{array}$ & T tube & 55 & 19 & 8 & No \\
\hline 9 & $\begin{array}{l}\text { Bile duct } \\
\text { confluence }\end{array}$ & Bilateral lobes & Open & 25 & 27 & 3 & No \\
\hline 10 & $\begin{array}{l}\text { Right hepatic } \\
\text { duct }\end{array}$ & Sgts VI-VII & Open & 30 & 14 & 1 & No \\
\hline 11 & Sgts II-III & Bilateral lobes & T tube & 65 & 36 & 6 & No \\
\hline 12 & Sgt VI & Sgt VI & Open & 35 & 44 & 1 & No \\
\hline 13 & Sgt VII & Right lobe & T-tube & 35 & 33 & 2 & No \\
\hline 14 & Sgts II-III & Sgts $\|-|\||$ & Open & 40 & 19 & 1 & No \\
\hline 15 & Sgts VI-VII & Right lobe & T tube & 50 & 25 & 2 & No \\
\hline
\end{tabular}

CBD common bile duct, Sgt segment

hepatolithiasis recurrence during follow-up. A 63-yearold male had a rapid stricture recurrence with multiple stones at the left lateral lobe after 3 months post initial intervention, and underwent open left lateral hepatectomy, but unfortunately developed pancreatic cancer at 36 months post stone clearance. Another 3 patients had hepatolithiasis recurrence at 23, 26, and 36 months post stone clearance, and all chose to receive conservative therapy other than surgical treatment. The other patients did not report any postoperative recurrence of hepatolithiasis or biliary stricture after stone clearance during the follow-up period, resulting in a recurrencefree rate of $73 \%$ at 2 years and $67 \%$ at 5 years (Fig. 2). Two patients did not have hepatolithiasis recurrence but suffered from severe cirrhosis and pancreatitis, respectively. The patient with severe cirrhosis had a background of secondary biliary cirrhosis due to long-term of bile duct stricture at the procedure, and passed away due to variceal bleeding at 20 months post stone clearance. No other patient mortality was observed, indicating a 5-year overall survival rate of $93 \%$ (Fig. 2).

\section{Discussions}

In this study we presented a novel method of hepatoliathiasis treatment to eliminate biliary stricture by Ho:
YAG laser ablation during cholangioscopy. During the follow-up period of 717 person years, our study cohort demonstrated a superior recurrence-free rate, and $2 / 3$ of the cohort individuals did not encounter stone recurrence. These results suggest that holmium laser ablation could be an effective approach for biliary stricture removal.

The holmium laser ablation is indicated in several clinical settings. The most common indication is biliary stricture with distal duct stones discovered during cholangioscopic exploration. Inappropriate managements, such as leaving the stricture intact, would results in residual hepatolithiasis stones in distal biliary duct and rapid recurrence of newly formed stones, even if the proximal duct stones had been clear. An alternative approach is surgical resection of the liver with biliary stricture, but it may cause significant blood loss and severe postoperative complications, especially in the patients with complicated biliary surgery history. Another indication of the laser ablation is biliary duct recanalization from the distal end in percutaneous transhepatic cholangioscopy (PTCS), to restore natural biliary drainage intrahepatically and to reduce future recurrence. Untreated biliary strictures during transhepatic cholangioscopy would block the cholangioscope from further inspection of the common bile duct, and could eventually induce stone recurrence 
Table 3 Long-term outcomes post laser ablation of biliary stricture

\begin{tabular}{|c|c|c|c|c|c|c|}
\hline $\begin{array}{l}\text { Case } \\
\#\end{array}$ & $\begin{array}{l}\text { Follow-up } \\
\text { duration } \\
\text { (months) }\end{array}$ & $\begin{array}{l}\text { Recurrence of hepatolithiasis } \\
\text { (time post stone clearance) }\end{array}$ & $\begin{array}{l}\text { Recurrence of biliary stricture } \\
\text { (time post stone clearance) }\end{array}$ & $\begin{array}{l}\text { Other long-term outcomes } \\
\text { (time post stone clearance) }\end{array}$ & $\begin{array}{l}\text { Overall } \\
\text { survival } \\
\text { (months) }\end{array}$ & $\begin{array}{l}\text { Recurrence-free } \\
\text { survival (months) }\end{array}$ \\
\hline 1 & 47 & $\begin{array}{l}\text { Yes, multiple stones at left } \\
\text { lateral lobe ( } 3 \text { months) }\end{array}$ & Yes (3 months) & $\begin{array}{l}\text { Pancreatic cancer ( } 36 \\
\text { months) }\end{array}$ & 47 & 3 \\
\hline 2 & 42 & No & No & No & 42 & 42 \\
\hline 3 & 67 & No & No & No & 67 & 67 \\
\hline 4 & 48 & $\begin{array}{l}\text { Yes, multiple stones at right } \\
\text { lobe and CBD ( } 26 \text { months) }\end{array}$ & No & No & 48 & 26 \\
\hline 5 & 49 & No & No & No & 49 & 49 \\
\hline 6 & 57 & No & No & No & 57 & 57 \\
\hline 7 & 46 & No & No & No & 45 & 45 \\
\hline 8 & 68 & No & No & No & 68 & 68 \\
\hline 9 & 40 & No & No & No & 40 & 40 \\
\hline 10 & 47 & No & No & No & 47 & 47 \\
\hline 11 & 20 & No & No & $\begin{array}{l}\text { Cirrhosis-associated death } \\
\text { (20 months) }\end{array}$ & 20 & 20 \\
\hline 12 & 55 & No & No & Pancreatitis (30 months) & 55 & 55 \\
\hline 13 & 39 & $\begin{array}{l}\text { Yes, multiple CBD stones ( } 23 \\
\text { months) }\end{array}$ & No & No & 39 & 23 \\
\hline 14 & 46 & No & No & No & 45 & 45 \\
\hline 15 & 48 & $\begin{array}{l}\text { Yes, multiple CBD stones ( } 36 \\
\text { months) }\end{array}$ & No & No & 48 & 36 \\
\hline
\end{tabular}

CBD common bile duct

due to impaired biliary patency. Therefore, the holmium laser ablation, due to its advantage of minimal invasiveness, is now the first choice for recurrent biliary stricture in our hospitals, after the initial surgical treatments lead to massive adherence and fast recurrence.
Holmium laser delivers pulsatile high energy to fragment bilious stones, which could easily cut the stricture tissue $[21,22]$. Based on our experience, some membranelike biliary strictures could be easily managed with a single and short episode of holmium laser ablation, and the

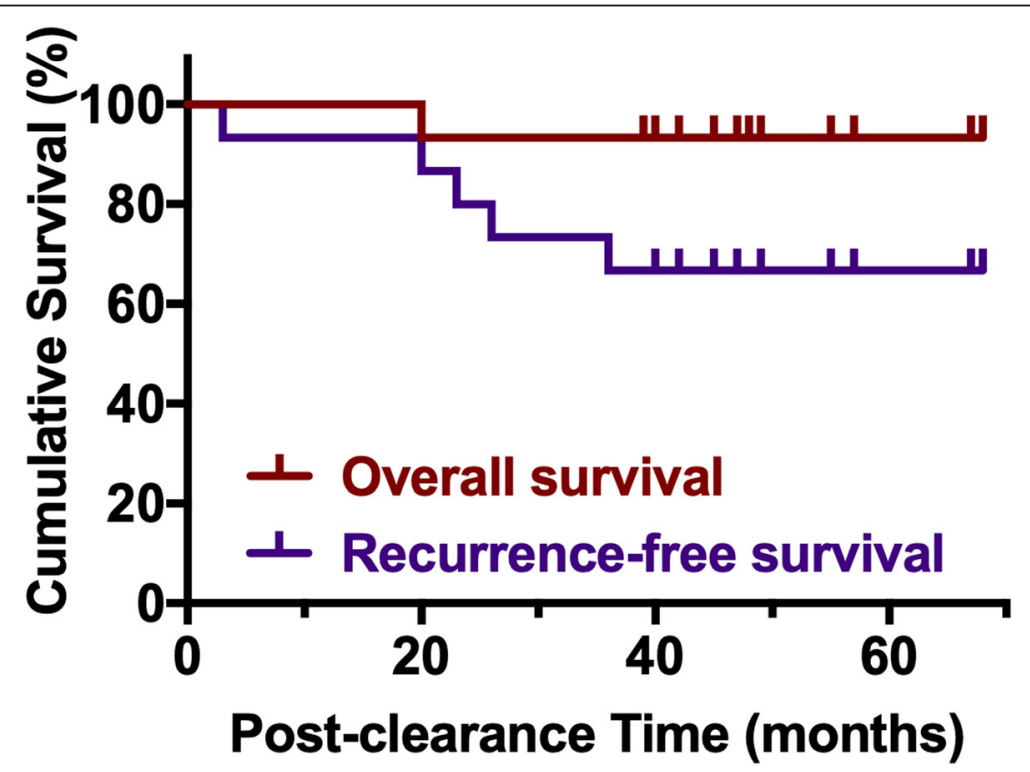

Fig. 2 Overall (red) and recurrence-free (purple) survival of patients post laser stricture ablation and stone clearance via cholangioscopies 
stricture will spontaneously relieve itself by biliary ductal flexibility. Other kinds of adherence biliary strictures require a longer working episode of holmium laser and a spiral maneuver to be completely eliminated.

Meanwhile, the prolonged working episode of holmium ablation might raise the concern of excessive injury and biliary hemorrhage. In a few cases, mild biliary hemorrhage could be well controlled by a further holmium laser hemostatsis at the same beaming frequency and energy as ablation. However, we have not encountered any case of uncontrolled active biliary bleeding yet. In our previous experience of other biliary surgery cases, temporarily blocking the entry route of cholangioscopy to increase the intraluminal pressure of intrahepatic biliary duct may help to stop uncontrolled biliary bleeding. Within the reach of cholangioscopy, biliary hemorrhage could also be managed by using biliary stent to create focal pressure on the bleeding site [23]. The crisis of uncontrolled biliary hemorrhage could at last be managed with interventional radiology or emergency open laparotomy as well.

Comparing to other techniques previously reported [15-20], the holmium laser ablation approach for biliary stricture shows several advantages. Firstly, the holmium laser ablation achieved a lower recurrence rate, which might benefit from more precise targeting, easier dilation, fewer scar formation, and less foreign substance retention in the biliary duct. Secondly, the holmium laser is originally designated for lithotripsy, and could be directly used for stricture ablation, therefore saving the surgeons' time to change to new devices usually requiring additional learning. Finally, the shared device with lithotripsy also reduces the surgical cost on medical device, making the holmium laser ablation the most cost-effect approach among other techniques. Notably, the holmium laser ablation could be performed in combination with balloon dilation to accomplish better effect to relieve biliary stricture.

Our study also had several limitations. The first limitation is due to the study population, which had a small size and only included Chinese adult patients. The technique will be verified in a larger number of patients in the future, with homogeneous subgroups classified according to etiology, location, and number of the biliary stenosis. The second limitation is the follow-up duration, which is proper to evaluate the stone recurrence rate, but relatively short to allow better evaluation of late complications.

\section{Conclusions}

In conclusion, we developed a novel technique of biliary stricture removal by cholangioscopic holmium laser ablation with satisfying clinical outcomes. The stricture removal allows for cholangioscopic lithotripsy in more endoscopic settings such as distal-to-proximal PTCS approach, broadening the minimally invasive applications of endoscopic interventions against hepatolithiasis. Since hepatolithiasis manifests as a chronic disease, future research should be focused on technique upgrades to persistently prevent stricture formation and to efficiently reduce hepatolithiasis recurrence during the long followup period.

\begin{abstract}
Abbreviations
Ho:YAG: holmium:yttrium-aluminum-garnet; PTCS: percutaneous transhepatic cholangioscopy; s.d.: standard deviation

\section{Acknowledgements}

The authors thank Mr. Jianfeng Wang for his assistance in recording cholangioscopy videos and Dr. Wenyue Wu of Harvard University for language polishing. The authors also thank the multidisciplinary treatment group of hepatobiliary and pancreatic diseases of the Second Affiliated Hospital, Zhejiang University School of Medicine for their helpful advice in patient management.
\end{abstract}

\section{Authors' contributions}

Study conception and design: JL, QH. Acquisition of data: QH, TM, WC, JW, PP. Analysis and interpretation of data: QH, TM, WC, JW. Drafting of manuscript: QH, PP. Critical revision of manuscript: JL. All authors have read and approved the manuscript.

\section{Funding}

This work was supported financially by the National Natural Science Foundation of China (81972207 and 81502026) and Zhejiang Provincial Natural Science Foundation (LQ16H180002 and LY18H160026). The funding body had no role in study design, data collection, analysis, and interpretation of data, and writing the manuscript.

Availability of data and materials

All data generated or analysed during this study are included in this article.

\section{Ethics approval and consent to participate}

This study was performed in accordance with the Declaration of Helsinki and human experimentation ethically approved by the institutional review board of the Second Affiliated Hospital, Zhejiang University School of Medicine (approval number 2012-355). The committee is constituted in accordance with the Governance arrangements for research ethics and complies fully with standard operating procedures for research committees in China. All subjects were over the age of 18 and gave written informed consent to receive the procedure described in this study.

\section{Consent for publication}

Written informed consent was obtained from the patients for publication of this work and any accompanying images. A copy of the written consents is available for review by the Editor of this journal.

\section{Competing interests}

The authors declare that they have no competing interests.

\section{Author details}

'Department of Hepatobiliary and Pancreatic Surgery, Second Affiliated Hospital, Zhejiang University School of Medicine, 88 Jiefang Rd, Hangzhou 310009, Zhejiang, China. ${ }^{2}$ Department of Hepatobiliary and Pancreatic Surgery, First Affiliated Hospital, Zhejiang University School of Medicine, 79 Qingchun Rd, Hangzhou 310003, Zhejiang, China.

Received: 3 August 2019 Accepted: 14 October 2019

Published online: 01 November 2019

References

1. Su CH, Lui WY, P'Eng FK. Relative prevalence of gallstone diseases in Taiwan. A nationwide cooperative study. Dig Dis Sci. 1992;37:764-8.

2. Kim MH, Lim BC, Myung SJ, Lee SK, Ohrr HC, Kim YT, et al. Epidemiological study on Korean gallstone disease: a nationwide cooperative study. Dig Dis Sci. 1999;44:1674-83.

3. Park YH, Park SJ, Jang JY, Ahn YJ, Park YC, Yoon YB, et al. Changing patterns of gallstone disease in Korea. World J Surg. 2004;28:206-10. 
4. Tazuma S. Gallstone disease: epidemiology, pathogenesis, and classification of biliary stones (common bile duct and intrahepatic). Best Pract Res Clin Gastroenterol. 2006;20:1075-83.

5. Liang T, Su W, Zhang Q, Li G, Gao S, Lou J, et al. Roles of sphincter of Oddi laxity in bile duct microenvironment in patients with Cholangiolithiasis: from the perspective of the microbiome and Metabolome. J Am Coll Surg. 2016;222:269-80 e10

6. Jeng KS, Sheen IS, Yang FS, Cheng SJ, Ohta I. Percutaneous transhepatic placement of metallic stents in the treatment of complicated intrahepatic biliary stricture with hepatolithiasis: a preliminary report. Am J Gastroenterol. 1999:94(12):3507-12.

7. He X, Liu Q. Diagnosis and treatment of hepatolithiasis (in Chinese). Chin J Dig Surg. 2015;14:275-9.

8. Li SQ, Liang LJ, Peng BG, Hua YP, Lv MD, Fu SJ, et al. Outcomes of liver resection for intrahepatic stones: a comparative study of unilateral versus bilateral disease. Ann Surg. 2012;255:946-53.

9. Chen DW, Tung-Ping Poon R, LiU CL, Fan ST, Wong J. Immediate and long-term outcomes of hepatectomy for hepatolithiasis. Surgery. 2004; 135:386-93.

10. Suzuki Y, Mori T, Abe N, Sugiyama M, Atomi Y. Predictive factors for cholangiocarcinoma associated with hepatolithiasis determined on the basis of Japanese multicenter study. Hepatol Res. 2012;42:166-70.

11. Huang MH, Chen CH, Yang JC, Yang CC, Yeh YH, Chou DA, et al. Long-term outcome of percutaneous transhepatic cholangioscopic lithotomy for hepatolithiasis. Am J Gastroenterol. 2003;98:2655-62.

12. Yoshida J, Chijiiwa K, Shimizu S, Sato H, Tanaka M. Hepatolithiasis: outcome of cholangioscopic lithotomy and dilation of bile duct stricture. Surgery. 1998;123:421-6.

13. Yoshimoto H, Ikeda S, Tanaka M, Matsumoto S, Kuroda Y. Choledochoscopic electrohydraulic lithotripsy and lithotomy for stones in the common bile duct, intrahepatic ducts, and gallbladder. Ann Surg. 1989;210:576-82.

14. Chen C, Huang M, Yang J, Yang C, Yeh Y, Wu H, et al. Reappraisal of percutaneous transhepatic cholangioscopic lithotomy for primary hepatolithiasis. Surg Endosc. 2005;19:505-9.

15. Jeng KS, Yang FS, Chiang HJ, Ohta I. Bile duct stents in the management of hepatolithiasis with long-segment intrahepatic biliary strictures. Br J Surg. 1992;79:663-6.

16. Larghi A, Rimbas M, Attili F, Kunda R. Endoscopic holmium laser lithotripsy of symptomatic gallstones through a lumen-apposing self-expandable metal stent. Am J Gastroenterol. 2016;111:1516.

17. Schoonjans R, De Man M, Aerts P, Van der Spek P, Van Steenberge R, Lepoutre L. Combined percutaneous balloon dilation and extracorporeal shock wave lithotripsy for treatment of biliary stricture and common bile duct stones. Am J Gastroenterol. 1994:89:1573-6.

18. Freeman ML, Cass OW, Dailey J. Dilation of high-grade pancreatic and biliary ductal strictures with small-caliber angioplasty balloons. Gastrointest Endosc. 2001;54:89-92

19. Ogura T, Onda S, Sano T, Takagi W, Okuda A, Miyano A, et al. Evaluation of the safety of endoscopic radiofrequency ablation for malignant biliary stricture using a digital peroral cholangioscope (with videos). Dig Endosc. 2017;29:712-7.

20. Nakahara K, Michikawa Y, Morita R, Suetani K, Morita N, Sato J, et al. Diagnostic ability of endoscopic bile cytology using a newly designed biliary scraper for biliary strictures. Dig Dis Sci. 2019;64:241-8.

21. Tarman GJ, Lenert JT, Hall L, Kane CJ. Holmium:YAG laser lithotripsy of intrahepatic biliary calculi. J Endourol. 1999;13:381-3.

22. Nakagawa A, Hirano $T$, Jokura $H$, Uenohara H, Ohki T, Hashimoto $T$, et al. Pulsed holmium:yttrium-aluminum-garnet laser-induced liquid jet as a novel dissection device in neuroendoscopic surgery. J Neurosurg. 2004;101:145-50.

23. Shinjo K, Matsubayashi H, Matsui T, Kawata N, Uemura S, Yamamoto Y, et al. Biliary hemostasis using an endoscopic plastic stent placement for uncontrolled hemobilia caused by transpapillary forceps biopsy (with video). Clin J Gastroenterol. 2016:9:86-8.

\section{Publisher's Note}

Springer Nature remains neutral with regard to jurisdictional claims in published maps and institutional affiliations.

Ready to submit your research? Choose BMC and benefit from:

- fast, convenient online submission

- thorough peer review by experienced researchers in your field

- rapid publication on acceptance

- support for research data, including large and complex data types

- gold Open Access which fosters wider collaboration and increased citations

- maximum visibility for your research: over $100 \mathrm{M}$ website views per year

At BMC, research is always in progress.

Learn more biomedcentral.com/submissions 